\title{
EDUCAÇÃO E ARTE NO MEIO PESQUEIRO: TECENDO AS EXPRESSÕES ARTISTICAS DE MULHERES E HOMENS DO SAL NO ESTADO DO PARÁ
}

Elida Moura Figueiredo ${ }^{1}$

Graça Santana $^{2}$

RESUMO: O trabalho em epígrafe visa divulgar o fazer artístico de mulheres e homens a partir de duas realidades: da APA de Algodoal/Maiandeua, município de Maracanã e da Reserva Extrativista Marinha "Mãe Grande", no município de Curuçá, ambos localizados na Zona do Salgado, no nordeste paraense. O artigo se justifica na medida em que, se tratando de região amazônica, há sempre descobertas a serem feitas e lacunas a serem preenchidas principalmente no que se refere às realidades que envolvem as populações pesqueiras. Um dos exemplos destas lacunas diz respeito aos raros estudos sobre as artes produzidas por mulheres e homens que lidam com a pesca na Amazônia Brasileira. O artigo é fruto de leituras e observações durante as pesquisas de campo no contexto do Grupo de Pesquisa RENAS da Coordenação de Ciências Humanas do Museu Paraense Emílio Goeldi, que mais de duas décadas realiza pesquisas entre estas populações na Amazônia Brasileira. As pesquisas do RENAS tem sido realizado principalmente, em pequenas unidades sociais, localizadas nas margens dos estuários, rios, igarapés, ilhas, enseadas e, povoados, vilas, e pequenas cidades que fazem parte dos municípios da zona do Salgado no litoral paraense, região onde se encontram as duas UCs acima mencionadas.

Palavras-Chave: Artesanato; Unidades de Conservação; Populações pesqueiras; Gênero.

${ }^{1}$ Bibliotecária, Especialista em Meio Ambiente, Mestre em Ciências Ambientais. Professora Substituta da Faculdade de Biblioteconomia da UFPA. Atualmente está vinculada a Secretaria de Estado de Ciência, Tecnologia e Inovação (PA). E-mail: elidapa@yahoo.com.br.

${ }^{2}$ Geógrafa, Especialista em Teoria Antropológica e Educação Ambiental. Está vinculada ao Museu Goeldi/MCT. E-mail: santana@museu-goeldi.br.

Revbea, Rio Grande, V. 8, N² 2:103-117, 2013. 


\section{INTRODUÇÃO \\ O CENÁRIO}

Mulheres e Homens do Sal é uma referência às populações que tradicionalmente vivem dos recursos aquáticos na Microrregião do Salgado, na Costa Atlântica do Estado do Pará, Amazônia Brasileira, que

[....] dependem tradicional e economicamente do manejo dos ecossistemas aquáticos no Estado do Pará e exploram o meio ambiente envolvente (o mar e ris costeiros, as pontas de água, as pedras, as baias existentes nos estuários dos rios, as enseadas, as praias, e suas beiras, os mangues, tintais, siriubais, os rios, furos, paranás e lagos interiores) de forma diversificada através da pesca, da coleta e extrativismo, cujo produto perpassa uma cadeia produtiva envolvendo diferentes categorias de atores sociais no contexto destas populações haliêuticas. Além daquelas que se encontram em zonas flúviolacustres ao longo do Rio Amazonas e lagos interiores nos municípios de Óbidos, Santarém, Monte Alegre; e em zonas de estuários: ao longo do rio Pará, nos município de Abaetetuba e Barcarena. (FURTADO; NASCIMENTO, 2002).

Neste sentido, este trabalho visa divulgar o fazer artístico de mulheres e homens a partir de duas realidades: da APA de Algodoal/Maiandeua, no município de Maracanã e da Reserva Extrativista Marinha "Mãe Grande", no município de Curuçá, ambos localizados na Zona do Salgado, região Nordeste do estado do Pará.

$\mathrm{O}$ artigo se justifica na medida em que, se tratando de região amazônica, há sempre descobertas a serem feitas e lacunas a serem preenchidas, principalmente no que se refere às realidades que envolvem as populações tradicionais. Um dos exemplos destas lacunas diz respeito aos raros estudos sobre as artes produzidas por mulheres e homens que lidam com a pesca na Amazônia Brasileira.

Dessa forma, o estudo ora apresentado, é fruto de leituras e observações surgidas durante pesquisas de campo no contexto do Grupo de Pesquisa RENAS da Coordenação de Ciências Humanas $(\mathrm{CCH})$ do Museu Paraense Emílio Goeldi (MPEG), que há mais de duas décadas realiza pesquisas entre estas populações na Amazônia Brasileira. As pesquisas do RENAS tem sido realizadas principalmente, em pequenas unidades sociais, localizadas às margens dos estuários, rios, igarapés, ilhas, enseadas e, povoados, vilas, e pequenas cidades que fazem parte dos municípios da Zona do Salgado, principalmente no litoral paraense, região onde se encontram as duas Unidades de Conservação (UC) acima mencionadas.

Revbea, Rio Grande, V. 8, № 2:103-117, 2013. 
Apesar do projeto RENAS se estender para outras regiões do Estado do Pará, vale ressaltar que este artigo tem como referencial apenas as expressões artísticas produzidas por mulheres e homens, que vivem nas duas UCs na região costeiras do litoral paraense.

Outra fonte de inspiração para a escolha do tema e elaboração deste artigo foram os resultados dos trabalhos voluntários na coordenação (2003/2007) da ONG Grupo Ambiental de Fortalezinha (GAF), existente na comunidade de Fortalezinha, onde há mais de dez anos realiza ações de Educação Ambiental entre as famílias de pescadores das quatro comunidades (Algodoal, Fortalezinha, Mocooca e Camboinha) da Área de Proteção Ambiental (APA) de Algodoal/Maiandeua, município de Maracanã.

Desta forma o artigo inicia apresentando o cenário de tradição destas pesquisas e mostrando o lugar de onde se está falando.

Belém, capital do Estado do Pará é o ponto de partida para se conhecer a microrregião do Salgado constituída por 11 municípios dentre eles Maracanã e Curuçá, onde se encontra as duas UCs acima mencionadas. A região faz parte da Costa Atlântica paraense e possui numerosas praias oceânicas com regime de marés como as de Salinas, Marudá, Algodoal, Ajuruteua e Romana nos município de Marapanim, Maracanã, Bragança e Curuçá, respectivamente.

Nesta área existem extensos manguezais e uma rica variedade de vegetais e animais, bem como, uma rede hidrográfica formadas por rios, baias, igarapés, furos e estuários, que banham e entrecortam os municípios, os pequenos povoados e cidades que localizam-se em suas margens, tornando muitas delas pólos turísticos e de pesca. È uma região de fácil acesso devido à variedade de transportes (terrestres e fluviais).

A microrregião do Salgado pertence é uma das microrregiões do estado brasileiro do Pará pertencente à mesorregião do Nordeste paraense (Figura 1). Sua população foi estimada em 2010 pelo IBGE em 247.364 habitantes em uma área total de $5.784,561 \mathrm{~km}^{2}$, dividida em onze municípios (Colares, Curuçá, Magalhães Barata, Maracanã, Marapanim, Salinópolis, São Caetano de Odivelas, São. João da Ponta, São João de Pirabas, Terra Alta, Vigia)

A região destaca-se culturalmente pelo ritmo do Carimbó, dança folclórica típica do Pará que se espalha por toda a região, com direito a formação de grupos que aprendem com os mestres o toque dos tambores, a música e a dança que apresentam principalmente para turistas em suas localidades, e em pequenos e grandes eventos na capital, onde são convidados.

A riqueza cultural inclui também, as igrejas e os casarios antigos, os festejos de São Benedito, da Marujada (dança de origem negra), o Boi Tinga e dos Cordões de Pássaros, que se apresentam no mês de junho, as procissões de santos, que marcam o calendário de todas as comunidades, o rico artesanato tradicional e direcionado, para a pesca e agricultura, o imaginário, 
onde a flora, a fauna e a gastronomia de alimentos e bebidas, possui um grande valor cultural.

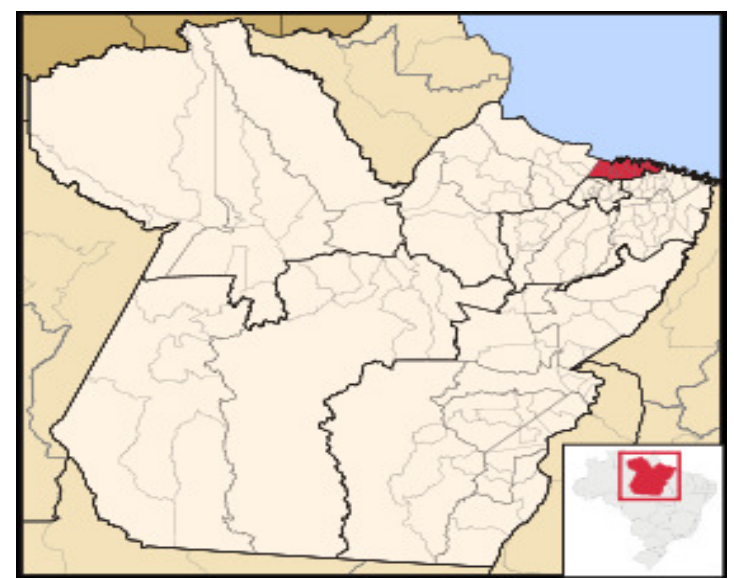

Figura 1: Mapa da Microrregião do Salgado.

Fonte: pt.wikipedia.org/wiki/Microrregião do Salgado. Acesso em: 20/102009

Segundo Quaresma (2003 apud FIGUEIREDO; SANTANA 2007), a ilha de Algodoal/Maiandeua, surgiu no quadro ambientalista brasileiro, na década de 70 , com a intenção de ser criada ali uma comunidade alternativa. Entretanto, passou efetivamente à qualidade de APA na década de 90. Com 19 quilômetros quadrados de extensão, a lei que legitima sua criação (Lei 5.621) foi promulgada em 27 de Novembro de 1990, a qual dispõe sobre a criação da referida APA no município de Maracanã (PA), com a finalidade de preservar a natureza e as belezas cênicas locais, além de vislumbrar possibilidades de um desenvolvimento sustentável local a partir da implantação do turismo ecológico na área.

A ilha localiza-se na parte mais extrema do arquipélago que fica ao Norte do município de Maracanã, a $300 \mathrm{~km}$ de Belém, entre as coordenadas geográficas aproximadas $00^{\circ} 35^{\prime} 03^{\prime \prime}$ a 003' 29" de latitude Sul, e 47운 31' $54^{\prime \prime}$ a 47⒊ 34"57" de longitude Oeste (Figura 2). São 2.378 há de ilha onde pode-se encontrar quatro comunidades (Algodoal, Camboinha, Mocooca e Fortalezinha). Maiandeua limita-se ao Norte, pelo Oceano Atlântico, ao Sul, pelo furo do Mocooca, a Leste, pela Baía de Maracanã e a Oeste, pela Baia de Marapanim. É considerada um dos atrativos turísticos mais belos e aprazíveis do Estado do Pará.

Sua cobertura vegetal é constituída, predominantemente, por manguezais, apicuns, restingas e vegetação secundária (BASTOS, 1996).

A população residente na APA, constitui-se em sua maioria de famílias de pescadores artesanais e de pessoas de outros lugares que se estabeleceram na ilha e que vem contribuindo para mudar o perfil de uma comunidade tradicionalmente pesqueira. 


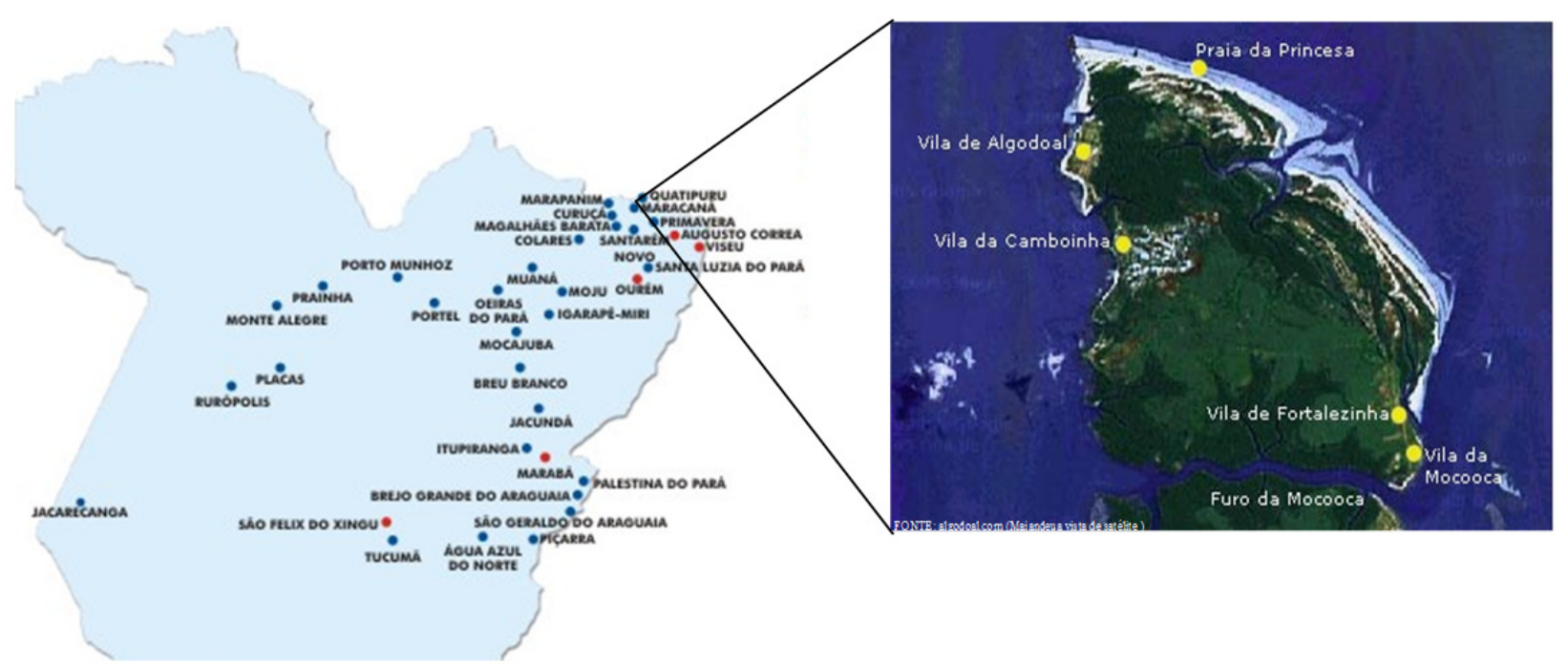

Figura 2: Mapa da ilha de Maiandeua, Município de Maracanã, Nordeste Paraense. Fonte: Adaptado de http://www.sebrae.com.br/udl/acoes para.htm e www.algodoal.com

Situado também na Microrregião do Salgado, encontra-se o município de Curuçá, que hoje abriga em seu território a Reserva Extrativista Marinha "Mãe Grande" (Figura 3). A RESEX é uma unidade de conservação criada pelo Decreto Presidencial em 13 de dezembro de 2002, numa área de 37.062.09 hectares no município de Curuçá, no estado do Pará, visando garantir o uso sustentável e a conservação dos recursos naturais, protegendo os meios de vida e a cultura da população extrativista local, de aproximadamente 3.000 famílias que vivem em 54 comunidades (FIGUEIREDO, 2007).

Curuçá faz parte da faixa do litoral brasileiro onde o rio Amazonas se encontra com o Oceano Atlântico, propiciando o aparecimento de uma variedade de peixes, moluscos e crustáceos, bem como extensos bosques de manguezais e outros tipos de vegetação.

Neste município predomina uma cultura tradicional de pescadores artesanais que se distribuem nas inúmeras ilhas, igarapés, furos, praias, pequenos povoados e na sede do município.

Como vimos as duas UCs fazem parte de um bioma comum, ou seja, do bioma Amazônico e, portanto apresentam algumas semelhanças no que se referem a presença de mangues, rios, igarapés alimentados pela influência do mar, propiciando uma atividade pesqueira, bastante diversificada e intensa.

A APA de Algodoal/Maiandeua é administrada por órgãos estaduais, enquanto que a RESEX, por órgãos federais.

Os dois municípios onde se encontram as UCs são considerados pólos turísticos da Amazônia Atlântica e são UCs devido as transformações ambientais e sociais que ameaçam o equilíbrio dos ecossistemas presentes e a cultura das populações que milenarmente vivem nesta região. 


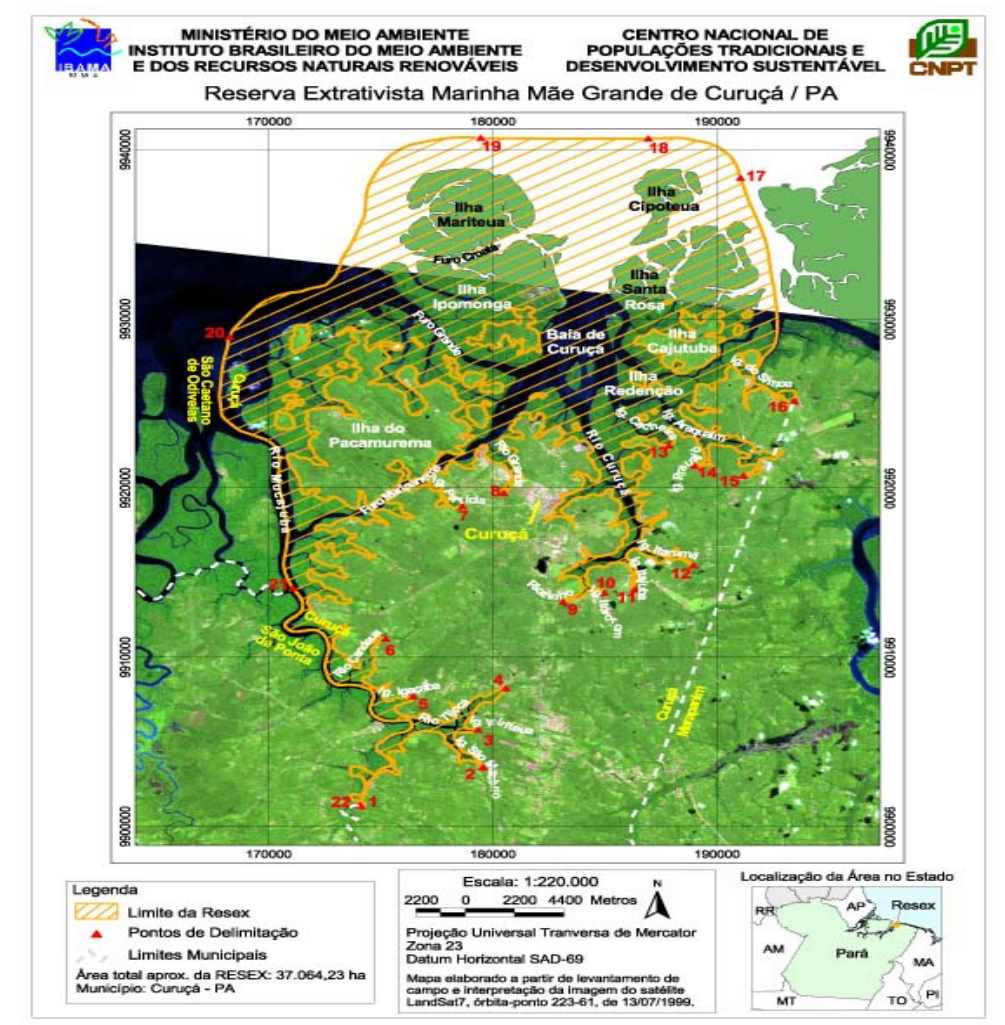

Figura 3: Delimitação da Área da Reserva Extrativista Marinha Mãe Grande, Curuçá-PA. Fonte: FURTADO, et al. 2003. (Inédito)

\section{ARTE E ARTESANATO (TECENDO ALGUNS PONTOS)}

Muitos têm se debruçado, filósofos, sociólogos, artistas, historiadores e bem como antropólogos, em busca da definição e do entendimento do que é arte e de suas diferenças, com o artesanato. Afinal, o que realmente são? Os mesmos se opõem? Quais as suas finalidades ou as suas especificidades? Onde são produzidos? Quais são os seus espaços? E seus públicos? A quem se destinam? Em que contextos devem ser inseridos?

Contudo, não é o propósito deste trabalho, enveredar pelos caminhos de definições ou diferenciações, mas sim tecer alguns pontos para esta discussão, que vem atingindo há algum tempo, um dos problemas mais tradicionais da cultura humana.

Assim o conceito de arte que permeia este trabalho é aquele que vislumbra na arte,

[...] um meio de identificação do homem com a natureza, com os outros homens e com o mundo, como meio de fazer o homem sentir e conviver com os demais, com tudo o que é e com que está para ser - está fadado a crescer na medida em que cresce o homem. (FISCHER, 1987, p. 253)

Revbea, Rio Grande, V. 8, № 2:103-117, 2013. 
O interesse pelos objetos manufaturados das culturas ameríndias teve início com a descoberta do Novo Mundo e ficaram conhecidas em toda a Europa, onde foram apreciadas mais pelo seu exotismo do que pela suas qualidades estéticas. Seu destino, era sobretudo o de integrar os gabinetes de curiosidades, precursores dos atuais museu, os quais eram ladeados por materiais heterogêneos de diversas procedências. (RIBEIRO; VELTHEM, 1992 apud VELTHEM, 2003, p.46)

Ressaltar hoje a produção manufaturada das populações tradicionais, especificamente a dos pescadores e pescadoras artesanais da Amazônia é enveredar pelos Museus e Casas de Culturas, aonde este objetos chegam pelas mãos de viajantes, pesquisadores, técnicos e representantes de comunidades e recebem um tratamento que garanta a sua conservação e apreciação futura em exposições, bem como, o seu registro e sua descrição dentro dos padrões museológicos.

A produção destes objetos faz parte da cultura material de populações pesqueiras, estudadas principalmente a partir da década de 70, pelo Museu Paraense Emilio Goeldi, na linha de pesquisa da Antropologia da Pesca, o que proporcionou a coleta de vários artefatos pesqueiros, como: paneiros, redes, abanos, agulhas, cestos, peneiras, miniaturas de barcos, remos e maquetes de currais, que fazem parte do Acervo Científico da Reserva Técnica Curt Nimuendajú do Museu Goeldi, a qual, conta também com aproximadamente 15.000 peças indígenas coletados por naturalistas, pesquisadores, tecnologistas dentre outros.

Assim, estes objetos são descritos e classificados no Livro de Tombo ou Livro de Registro como peças etnográficas seguindo o modelo museológico.

Vale lembrar, que nenhuns destes objetos são descritos e classificados fazendo-se uma relação como objetos artísticos, no entanto, o material indígena é tido como "objetos da arte indígena".

Com relação a esta questão Velthem (2003), afirma que

[...] na avaliação das produções indígenas persistem distorções que tem origem na imperiosa necessidade do pensamento ocidental de avaliar as artes das Américas a partir de seus próprios pressupostos $e$, nesse exercício transformar 0 desconhecido em algo conhecido. Posteriormente, a prolongada desconsideração de que essas artes foram alvos, as relegou ao âmbito da antropologia e dos museus de História Natural, conforme Roe (1995 apud Hussak, 2003). Paralelamente, foram e ainda são aquilatadas enquanto artesanato e, por conseguinte, são julgadas valorativamente, a partir do estabelecimento de uma distinção entre arte e artesanato. (VELTHEM, 2003, p.46) 
Fora do âmbito do Museu, os mesmos objetos de populações pesqueiras, são descritos e classificados por outros estudiosos na categoria de artesanato, onde destacam além da matéria prima, a técnica empregada na feitura dos mesmos e a função a que eles se destinam como: utilitários e decorativos, porém, não relacionam as mesmas como expressões artísticas.

Observamos, ainda, que alguns artistas plásticos expõem em galerias de arte, objetos considerados como artesanatos e oriundos das comunidades agro-pesqueiras, como por exemplo, os brinquedos de miriti, como objetos artísticos, buscando talvez encontrar elos que possam contribuir e diminuir 0 grande fosso que observamos na discussão entre Arte e Artesanato.

Cabe ressaltar que a radical separação entre o trabalho artístico (enquanto algo por excelência criativa e de qualidade refinada) das outras formas de trabalho surge com o aparecimento da sociedade moderna (ORTIZ, 1998; WOLFF, 1981, apud RAMALHO, 2009).

Segundo Dolabella et al. (2009, s/p),

revista brasileira

educação ambiental
[...] apresentar os conceitos de arte e artesanato, dentro de um contexto sociológico, não é tarefa das mais fáceis. Tal tarefa surge aqui como um conflito, mas todo conflito se torna inevitável e é sempre útil na medida em que define questões [...] Definir arte na atualidade é, antes de tudo, retomando o conceito de Duchamp, apontá-la como um espaço apropriado para a produção visual do século XX [...] A forma como é apresentada e/ou consumida determina um local definido para compreender também a sociedade e a forma de sua organização [...] Sobre o artesanato, que utiliza-se de matrizes que transformam-se com o decorrer da modernidade, não pode-se dizer que possui menor criatividade que a arte. $O$ mesmo, produzido por determinados grupos coletivos, ou indivíduos isolados dentro do tecido urbano, relaciona-se diretamente a um sentido prático do que e para que é feito função determinada quando são produzidos - que pode ser, por seu usuário (público), posteriormente modificada [...] Nos dias atuais, se dentro de uma sociedade urbana, o local de consumo da arte e do artesanato pode ser definido por galerias, museus, mercados ou feiras, a definição e diferenciação do que é culto ou popular deve passar por uma avaliação mais criteriosa dada a circulação de informações dentro de uma sociedade inteiramente massificada definindo formas de expressão - na arte e no artesanato - que se nutrem de uma mesma base [...] O que é arte" não é apenas uma questão estética: é necessário levar em conta como esta questão vai sendo respondida na interseção do que fazem os jornalistas e os críticos, os historiadores e os museógrafos, os marchands, os colecionadores e os especuladores. 
Além dos objetos acima mencionados que se encontram nos museu estas populações produzem outras modalidades de arte (pintura, esculturas, colagens, instalações, serigrafia em tecidos, grafismo em cuias) que se consolida no seu cotidiano e de certa forma nem sempre está relacionado ao artesanato, no entanto, são englobados na categoria de artesanato dificultando assim, a sua visibilidade como expressões próprias de quem vivem dos recursos pesqueiros. As mesmas são oriundas de um saber local, considerado como patrimônio que se inscrevem como expressão simbólica e material deste grupo social a partir do seu jeito de ser, estar e ver o mundo, no qual se encontram inseridos RAMALHO (2009). Estas expressões não estão desarticuladas do manejo e de conhecimentos das técnicas.

\section{GÊNERO, HISTÓRIAS E IMAGENS}

Assim, mulheres e homens do sal é uma contribuição aos estudos de gênero do Grupo de Pesquisa RENAS, onde se destacam os trabalhos de Maneschy, Alencar e Nascimento (1995) que reflete uma somatória de esforços que em conjunto com outros trabalhos já realizados por outros pesquisadores de outras instituições entre outros grupos sociais (MOTTA, 1997; ALVARES, SIMONIAN; D'INCAO; SANTOS 1995) poderá contribuir à efetivação de novas discussões apenas aqui iniciadas. $O$ artigo se justifica na medida em que, se tratando de região amazônica, há sempre descobertas a serem feitas e lacunas a serem preenchidas principalmente no que se refere às realidades que envolvem as populações pesqueiras. Um dos exemplos destas lacunas diz respeito aos raros estudos sobre as artes produzidas por mulheres e homens que lidam com a pesca na Amazônia Brasileira.

Nas comunidades pesqueiras amazônicas é comum observar que mãos habilidosas e pacientes de mulheres e homens continuam a dar forma a objetos utilizados na vida cotidiana. São canoas, montarias; tipitis, paneiros, esteiras, peneiras e abanos, trançados de palhas e talas; redes de pesca e puçás, tecidas em fios da naylon; potes, pratos e alguidares, modelados com barro, entre outros objetos, que fazem parte do dia-a-dia dessas comunidades. $\mathrm{E}$ ainda, coletam sementes, pintam em tecidos, esteiras e em objetos, cenários do seu meio ambiente, escavam pedaços de madeira transformando-as em figuras que lembram animais dos quais convivem ou de seu imaginário; coletam ossos de animais para colares, brincos e pulseiras.

De modo geral, as artes produzidas por mulheres e homens destas pequenas unidades sociais, que mais se destaca é o artesanato. Esta atividade tem incentivado a criação de políticas públicas de capacitação, principalmente pelo Serviço de Apoio às Micro e Pequenas Empresas (SEBRAE) e a organização social dos artesãos; bem como, criação de polos como, por exemplo, o polo de Abaetetuba, com os objetos de miriti, e Icoaraci em Belém com a cerâmica, dentre outros. $O$ artesanato tem despertado também 0 interesse de pesquisadores, dos meios de comunicação, como estratégia de trabalho e renda, e pouco se destaca que o mesmo é uma das formas de 
expressão artística, de interpretar e comunicar o mundo em que vivem.

Mulheres e homens dedicam suas horas livres para criar suas obras e muitos deixam à pesca e se profissionalizam neste ramo, onde aprendem novas técnicas, usos de ferramentas no aproveitamento e beneficiamento das matérias primas, bem como, conhecimentos sobre mercados, feiras, exposições e outros eventos culturais onde tem oportunidade de escoar sua produção.

Este cenário é observado no contexto das UCs em questão, que além da produção dos objetos tradicionais, produzem ainda outras formas de expressão já mencionadas acima que ainda não alcançam uma visibilidade desejada.

Na APA e na RESEX "Mãe Grade" as mulheres se movimentam muito mais em participar dos programas de capacitação promovidos pelos projetos existente na área como, por exemplo, o RENAS, do que os homens que se dedicam em suas horas livres a fazer outros artesanatos (colares, pulseiras, etc.), bem como (pintura, colagens, instalações e esculturas) e muitos são apontados como verdadeiros mestres, artistas ou bons artesãos e neste sentido apesar das mulheres fazerem e criarem seus trabalhos, não tem este status nas comunidades. Esta é uma situação que também é recorrente em Abaetetuba, onde só os homens são chamados de mestres, mas são as mulheres, segundo os artesãos entrevistados, que realizam a melhor pintura, o melhor acabamento das peças de miriti e muitas fazem brinquedos ou parte destes, ou seja, participam de todo o processo, no entanto, não são consideradas mestres, não reivindicam seus direitos quanto artesã, dizem ainda como as mulheres pescadoras, eu apoio o homem.

\section{EXPRESSÕES ARTÍSTICAS DE MULHERES E HOMENS NA ZONA DO SALGADO}

Segundo Battistoni Filho (1987, p.11),

O homem num determinado momento de sua criação, realizou a primeira descoberta: começou a usar a mão. A segunda descoberta foi a expressão, isto é , a linguagem e todos os expedientes através dos quais um homem se comunica com outro homem. A mão e a expressão são os órgãos da inteligência humana. São os instrumentos que permitem ao pensamento exercitar-se e colocar-se em relação com a realidade, com o mundo exterior.

As mulheres e homens do sal se expressam através de objetos que fazem parte de sua tradição que são utilizados nas atividades diárias de pesca, coleta e agricultura.

Produzem ainda, outras formas de expressões (pinturas, colagens, 
instalações, esculturas), como as apresentadas abaixo:

As pinturas (Figura 4) geralmente são imagens da natureza onde utilizam vários tipos de suporte, madeiras, nas paredes, portas, nos lados das embarcações, nos carros onde vendem comidas, nos e muros das casas Figura 5). Antigamente pintavam com carvão, argila e urucum.

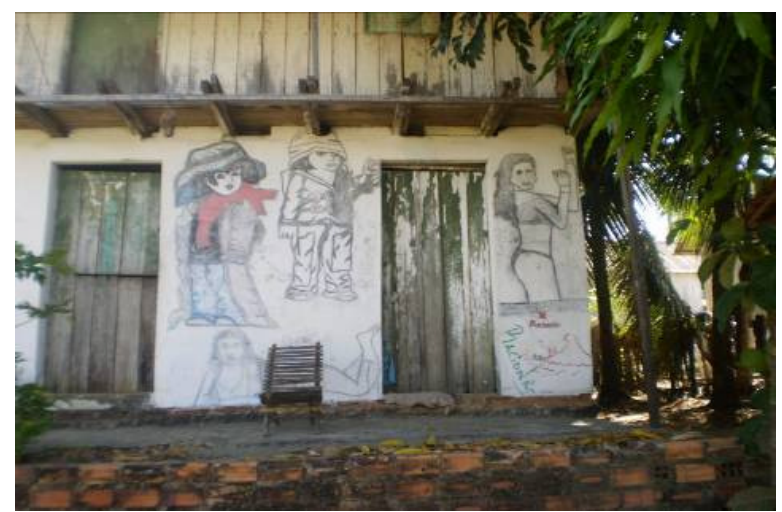

Figura 4: Pintura com carvão na parede de uma moradia. Foto: Graça Santana (2007)
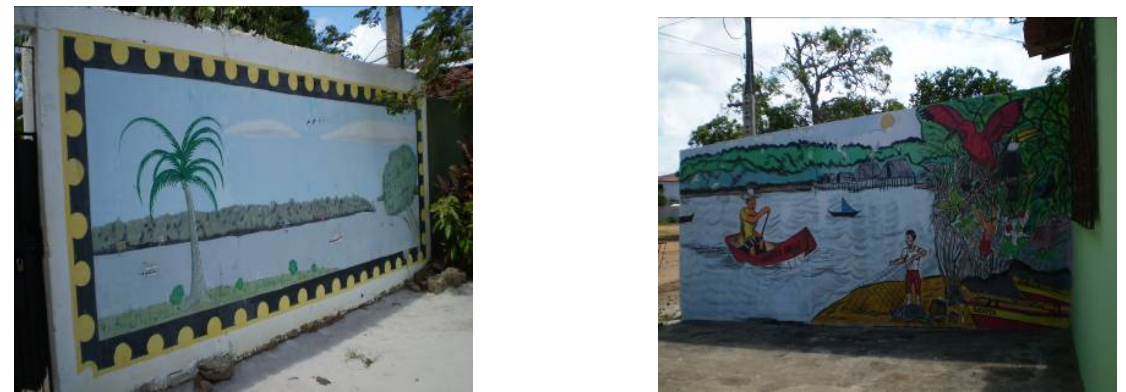

Figura 4: trabalhos de homens da RESEX de Curuçá: pinturas em muros. Foto: Lourdes Furtado (2009).

As colagens aproveitam restos de animais (crustáceos, moluscos, quelônios, peixes e mamíferos marinhos) encontrados durante a realização de seus trabalhos (Figura 6).
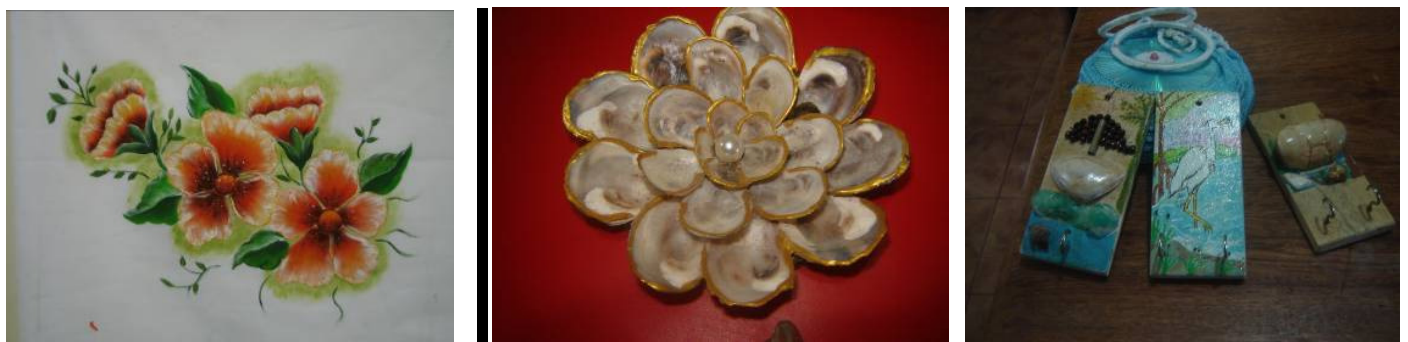

Figura 6: trabalhos mulheres da RESEX Mãe Grande de Curuçá: pinturas e colagens, pintura em tecido, colagens com ostras e pintura e colagem na madeira. Foto: Graça Santana (2009).

Revbea, Rio Grande, V. 8, № 2:103-117, 2013. 
As esculturas feitas com cocos representam rostos de pessoas e alguns animais como macacos.

As instalações são feitas com a união de varias formas e cores na busca de uma composição única.

Assim, procuramos de forma didática apresentar alguns trabalhos de mulheres e homens destacando a técnica e o seu lugar de origem (Figuras 7, 8 e 9).
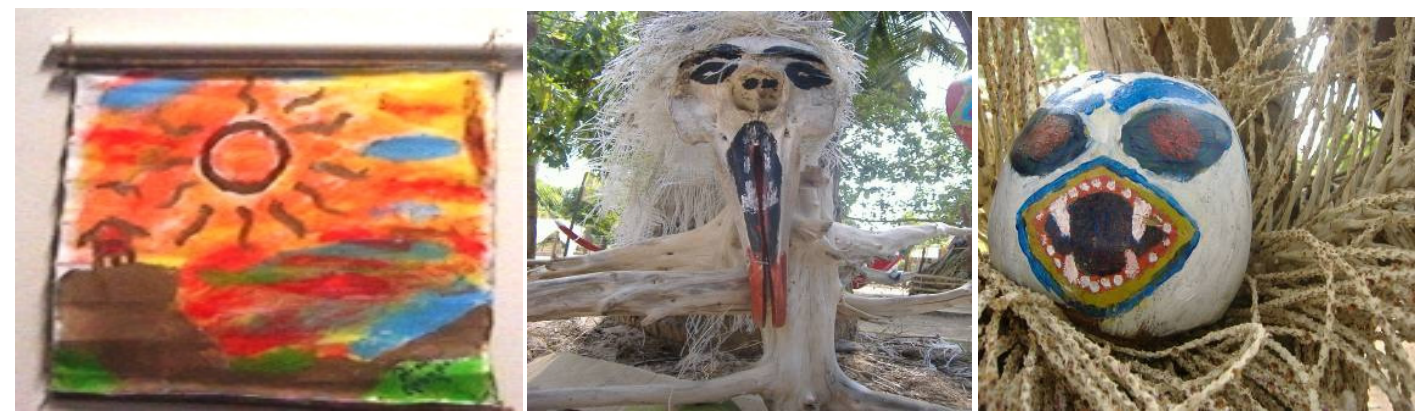

Figura 7: trabalhos de mulheres e homens da APA de Algodoal/Maiandeua na comunidade de Fortralezinha. Pintura em tela, instalações de plástico e coco. Fotos: Graça Santana (2009).
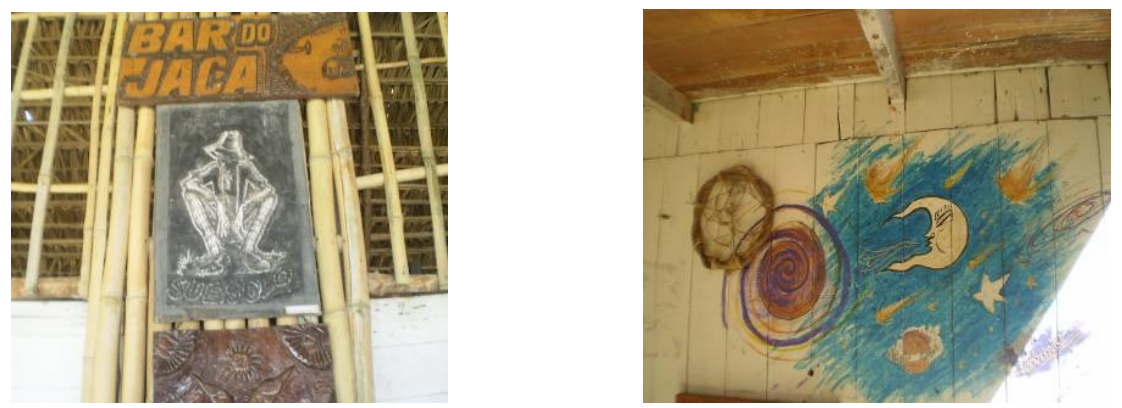

Figura 8: trabalhos de mulheres e homens da APA de Algodoal/Maiandeua, comunidade de Algodoal. Entalhe em madeira representando um Tocador de Carimbo e pintura na parede.
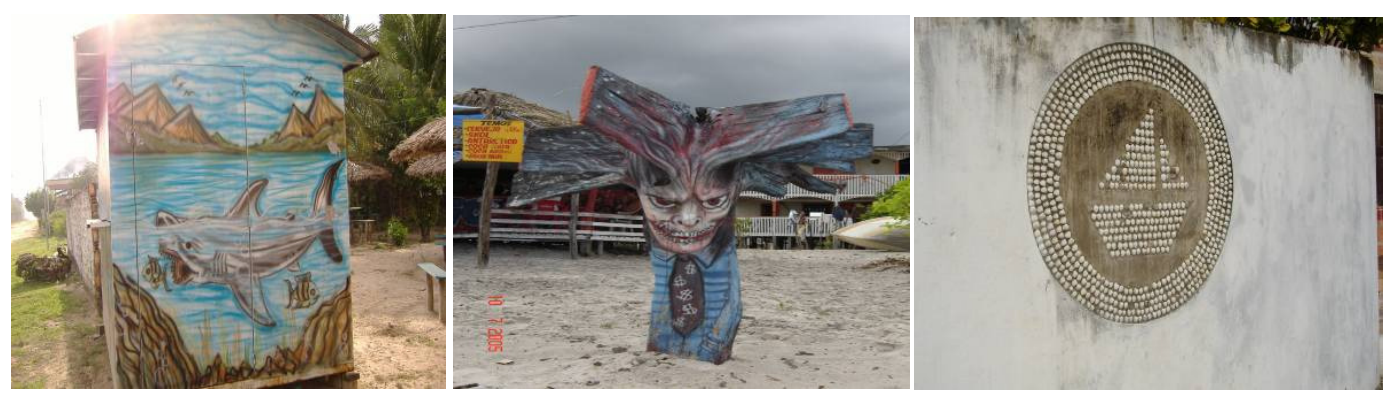

Figura 9: trabalhos de mulheres e homens da comunidade de Algodoal. Pintura em um carro de lanche; escultura em madeira e colagem em um muro da vila com conchas de sernambi, feitas por anônimos. 
Identificam outras formas presentes nos galhos, paus, raízes e pedras que coletam na mata, nas margens dos rios, igarapés galhos, que se parece com uma infinidade de coisas (cobras, rosto de mulher, peixes) entre outras formas (Figura 10). Estes materiais são levados para seus barracos onde são expostos como objetos de decoração, ou juntos com outros materiais formando verdadeiras instalações.

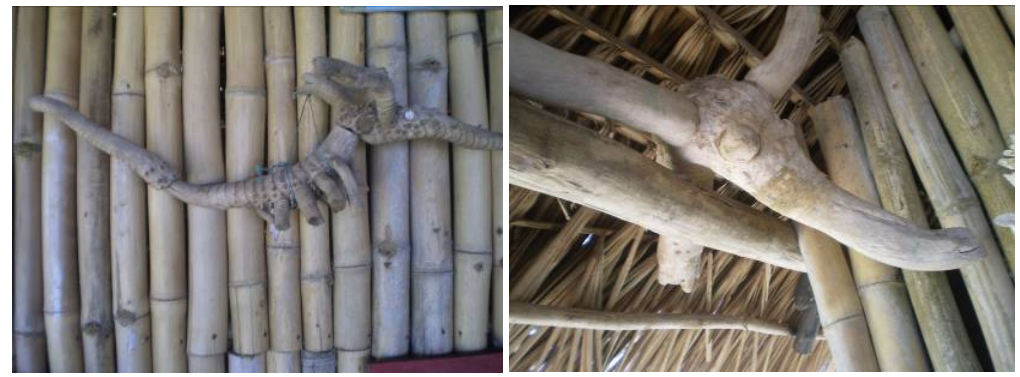

Figura 10: Raízes encontradas pelos pescadores na mata, associadas por eles como formas zoomorfas. Foto: Graça Santana (2009).
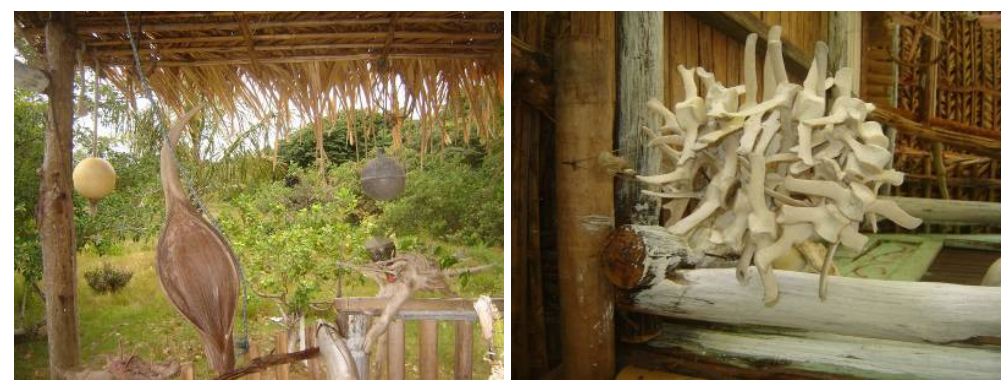

Figura 11: Folha de palmeira associadas por eles a um pássaro e móbile feito com ossos de animais marinhos encontrados na praia. Fotos: Graça Santana (2009).

São formas escultóricas encontradas na natureza que na imaginação destas pessoas podem representar uma arte, identificam como pássaros, corpo de mulher, cobras, dentre outros, geralmente coletadas por crianças (filhos de pescadores) durante a realização de trabalhos na mata, nas margens dos rios, igarapés, manguezais. Estes objetos às vezes não sofrem nenhuma interferência e são interpretadas de diversas maneiras por parte do grupo familiar e da comunidade em geral, que dão o seu palpite dizendo com que parece o galho de arvore ou a pedra, ou parte de ossos de animais, raízes que são expostas para decorar os barracos.

Segundo o crítico de arte e poeta Ferreira Gullar,

[...] o homem tem capacidade de identificar semelhanças das formas. Essa capacidade de identificar imagens, porém não é exclusiva do ser humano. Peixe também identifica. As pessoas fazem uma isca de metal fingindo ser um peixe, o peixe vem e morde, pensando que é outro peixe. Ele identifica formas. Porém, o que distingue o homem é a capacidade de produzir 
formas. Essa identificação gera no homem uma elaboração psicológica que gera outras reações, num processo diferente dos animais. (FERREIRA GULLAR, 1989)

Os barracos que constroem estão impregnados deste fazer artístico que se estende do interior das casas para as ruas, usam como suporte os muros das casas, as embarcações e em outros instrumentos de trabalho, onde utilizam uma infinidade de formas, cores, materiais e técnicas que exercitam dia-a-dia no convívio entre si e entre os outros, geralmente pessoas de fora das comunidades.

Esta produção está fora das galerias, dos museus, dos mercados ou feiras e não recebem patrocínios nem incentivos dos grandes mecenas da arte, da mídia, das políticas públicas, dos educadores da arte, dentre outros.

No entanto quando consultamos os sites da internet sobre a arte produzida por estas populações, a referência que temos sobre arte, esta relacionada com a arte de pesca que é a forma como se denominam nas ciências, na engenharia de pesca e mesmo na legislação pesqueiras os instrumentos ou aparelho usados para pescar, como as redes de pesca ou 0 anzol.

Acreditamos que esta denominação tem sua origem na definição que os pescadores e pescadores definem o seu trabalho na qualidade de arte, conforme Ramalho (2009) e acabam não dando visibilidade a outras formas de expressão artística.

A variedade da expressão artística é resultado da variedade de concepções que os seres humanos têm sobre como são e funcionam as coisas. Na realidade, é uma única variedade (GEERTZ, 1997, p.181). São práticas subjetivas e objetivas que tecem e moldam modos de vida e revelam particularidades sociais de sua cultura.

As artes produzidas por estas populações pesqueiras são resultados dos diversos meios, processos e objetos que se mantiveram desde pré-história e nos dias atuais dos recursos (FURTADO, 1987), bem como, dos recursos terrestres.

\section{REFERÊNCIAS}

ÁLVARES, M.L.M.; D'INCAO, M.A. A mulher existe? Uma contribuição ao estudo de mulher e gênero na Amazônia. Belém: GEPEM, 1995.

ALENCAR, E.F. Pescadeiras, Companheiros e Perigosas: a pesca feminina na itha dos Lençóis. Dissertação de Mestrado. Brasília. UNB. 1991. Inédito.

BASTOS, M.N. 1996. Caracterização das formações vegetais da restinga da praia da Princesa, Algodoal-Maiandeua-PA. Tese (doutorado). Universidade Federal do Pará/Museu Paraense Emílio Goeldi. Belém, 261 p.

BATTISTONI FILHO, D. Pequena historia da arte. 2. ed. Campinas: Papirus, 1987.

Revbea, Rio Grande, V. 8, № 2:103-117, 2013. 
D'INCAO, M.A. Sobre o amor na fronteira. In: ÁLVARES, M.L.M., D'INCAO, M.A. (Org.). A Mulher existe? uma contribuição ao estudo da mulher e gênero na Amazônia. Belém: GEPEM/GOELDI, 1995.

DOLABELLA, R.M. et al. Arte e artesanato em termos sociológicos: alguns conceitos. Disponível em: http://www.eba.ufmg.br/alunos/kurtnavigator/arteartesanato/conceitos.html. Acesso em: 10/10/2009.

FERREIRA GULLAR. A imagem como expressão estética. Anais do I Congresso Internacional - Imagem, tecnologia educação, n.1, Ago/set/out 1989. UFRJ.

FIGUEIREDO, E.M. Uma estrada na reserva: impactos sócio-ambientais da PA-136 em Mãe Grande, Curuçá (PA). Dissertação (Mestrado). Pós-Graduação em Ciências Ambientais. Universidade Federal do Pará/Museu Paraense Emilio Goeldi/Embrapa, Belém, 2007.

FISCHER, E. A necessidade da arte. 9 ed. Rio de Janeiro: Guanabara, 1987

FURTADO, L. G. Curralistas e redeiros de Marudá: pescadores do litoral do Pará. BELEM: CNPQ/MPEG/FALANGOLA, 1987.

FURTADO, L.G. ; NASCIMENTO, M.I.H. Traços de uma comunidade pesqueira no litoral amazônico: relato sobre organização em comunidades haliêuticas. In: FURTADO L.G.; QUARESMA, H.D.A.B. (Org.). Gente e Ambiente no Mundo da Pesca Artesanal. Belém-PA: Museu Paraense Emilio Goeldi, 2002.

FURTADO, L.G. et al. Diagnóstico etno-ecológico da Reserva Extrativista Marinha Mãe Grande, Curuçá, Zona do Salgado-Pará. Relatório de Viagem. Belém: Museu Paraense Emilio Goeldi, 2003. (Inédito)

GEERTZ, C. O saber local: novos ensaios em antropologia interpretativa. Tradução de Vera Mello Joscelyne. Petrópolis, Vozes, 1997, 366 pp.

MANESCHY, M.C.A.; ALENCAR, E., NASCIMENTO, I.H. Pescadoras em busca de cidadania. In: ÁLVARES, M.L.M., D'INCAO, M.A. (Org.). A Mulher existe? uma contribuição ao estudo da mulher e gênero na Amazônia. Belém: GEPEM/GOELDI, 1995.

MOTTA-MAUÉS, M.A. Trabalhadeiras e Camaradas: relações de gênero, simbolismo e ritualização numa comunidade Amazônica. Belém: CFCH/UFPA, 1993.

RAMALHO, C.W.N. Pescador Artesanal: arte da pesca o modo de vida. Disponível em: www.anppas.org.br/encontro anual/.../cristiano ramalho.pdf. Acesso em: 18/10/2009.

SANTOS, E F. Mulher - Mercadoria. In: ÁLVARES, M.L.M., D'INCAO, M.A. (Org.). A Mulher existe? uma contribuição ao estudo da mulher e gênero na Amazônia. Belém: GEPEM/GOELDI, 1995.

SIMONIAN, L.T. Mulheres seringueiras na amazônia: uma vida de trabalho silenciado. In: ÁLVARES, M.L.M., D'INCAO, M.A. (Org.). A Mulher existe? uma contribuição ao estudo da mulher e gênero na Amazônia. Belém: GEPEM/GOELDI, 1995.

VELTHEM, L.H.V. O belo é a fera: estética da produção artística e da predação entre os Wayana. Museu Nacional de Etnologia Assírio \& Alvim. 2003

WOLFF, J.A produção social da arte. Rio de Janeiro, Zahar. Editores, 1981. 